\title{
TRIBUTO A UM PENSADOR DO DESENVOLVIMENTO COM DIMENSÃO ESPACIAL
}

\author{
Hoyêdo Nunes Lins ${ }^{1}$ \\ UFSC \\ hoyedo.lins@ufsc.br
}

\section{Resumo}

Relato autobiográfico sobre a influência da leitura do livro Economia Política da Urbanização (1976) de Paul Singer na formação acadêmica e prática profissional no Instituto de Planejamento Urbano de Florianópolis (IPUF).

Palavras-chave: Paul Siger. Economia Política da Urbanização. Urbanismo. Instituto de Planejamento Urbano de Florianópolis (IPUF).

\section{TRIBUTE TO A THINKER OF DEVELOPMENT WITH SPACE DIMENSION}

\section{Abstract}

An autobiographical account of the influence of Paul Singer's book Political Economy of Urbanization (1976) on academic training and professional practice at the Institute of Urban Planning of Florianopolis (IPUF).

Keywords: Paul Siger. Political Economy of Urbanization. urbanism. Institute of Urban Planning of Florianopolis (IPUF).

\footnotetext{
${ }^{1}$ Professor Titular da Universidade Federal de Santa Catarina, lotado no Departamento de Economia e Relações Internacionais e docente dos programas de pós-graduação em Economia e em Relações Internacionais.
}

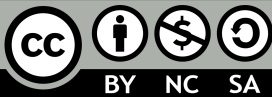

P2P \& INOVAÇÃO, Rio de Janeiro, v. 5 n. 1, Ed. Especial, p.16-25, 2018. 
Há autores cuja obra é reconhecida por seus leitores como tendo sido de grande importância para suas trajetórias profissionais, merecendo justa manifestação de agradecimento. De fato, expor a relevância das ideias e abordagens de alguém para o aprimoramento da forma como nos debruçamos sobre questões de interesse intelectual ou prático, permitindo abertura de perspectivas e a multiplicação das indagações, é procedimento que deve embutir gratidão.

Esse é tanto mais o caso na medida em que a assinalada influência repercute até mesmo em escolhas sobre a direção da carreira de quem, em diferentes circunstâncias, usufrui da obra. Em situações desse tipo, declarar a importância da produção intelectual e agradecer a inspiração dela emanada tornam-se, praticamente, uma coisa só.

Declaração nesses termos, com gratulação implícita, é o espírito deste texto, concebido como uma espécie de tributo ao professor Paul Singer e à obra por ele construída. O escrito combina registro de experiência pessoal, exibindo perfil de depoimento, e algumas considerações sobre a parte das publicações desse autor que produziu efeitos no sentido assinalado.

Paul Singer foi um autor prolífico, e escreveu sobre muitos assuntos. Ao longo de décadas, explorou ângulos da economia política que lhe permitiram tratar com acuidade e visão crítica questões relativas a temas tão instigantes como desigualdade, pobreza, distribuição de renda, trabalho e desemprego, entre vários outros.

Nas últimas décadas, concentrou-se na problemática da economia solidária, e não somente em termos acadêmicos ou intelectuais. A partir de meados de 2003, Singer liderou a Secretaria Nacional de Economia Solidária, criada no âmbito do então Ministério do Trabalho e Emprego. No alvo das ações dessa secretaria figurava com destaque a promoção do desenvolvimento na esfera local, por meio do funcionamento de cooperativas, entre outros instrumentos ou iniciativas.

O reconhecimento de importância aqui manifestado sobre a obra de Singer, refere-se ao que há de contribuições à reflexão e ao discernimento de medidas para estimular o desenvolvimento regional e urbano. Numa palavra, diz respeito ao que figura sobre o desenvolvimento com dimensão espacial.

Economia solidária e desenvolvimento local, que emergem, articulados, nas atividades de Singer desde o começo dos anos 2000, evocam a dimensão (também) espacial do desenvolvimento. Entretanto, o realce aqui contemplado relaciona-se à produção intelectual desse autor décadas atrás, notadamente nos anos 1970. A principal obra cogitada nesses termos 
é Economia Política da Urbanização (SINGER, 1976), livro cuja primeira publicação ocorreu no início daquela década, em 1973.

Para que essa manifestação de reconhecimento adquira sentido, é necessário relatar o que segue.

Obtive a formação em Ciências Econômicas, na Universidade Federal de Santa Catarina, entre 1973 e 1976. As pessoas que vivenciaram a universidade brasileira (em particular a de feição pública) durante os anos 1970, notadamente em cursos das ciências sociais aplicadas ou das ciências humanas, hão de recordar as dificuldades e tensões daquele período por conta do cerceador e intimidador quadro político e governamental.

Tal situação adversa se refletia, com maior ou menor intensidade, nas bibliografias utilizadas e na própria oferta de disciplinas, seja quanto ao rol ou ao caráter dos conteúdos disponibilizados. Desse modo, por mais que agora tente, custo a encontrar na memória registros de aulas ou de leituras sistemáticas sobre, por exemplo, pobreza urbana, desigualdades interregionais de desenvolvimento e movimentos sociais no campo ou na cidade, para mencionar somente alguns temas caros às abordagens críticas sobre as relações entre vida social e espaço.

Claro que, por exemplo, Celso Furtado nos colocava em contato, entre outros assuntos, com a questão nordestina, em Formação Econômica do Brasil (FURTADO, 1987). Contudo, esse tipo de assunto, tratado por Furtado ou por outros autores, nunca foi, até onde a lembrança agora atinge, objeto de discussão efetiva e consequente durante o curso.

Graduado sob tais condições, e sem entusiasmo particular com o que enxergava ao considerar possíveis cenários profissionais, ocorreu-me ser incorporado a uma equipe técnica montada por iniciativa da Prefeitura Municipal de Florianópolis para lidar com o planejamento do transporte urbano nessa cidade. Atuar em tal grupo, que era multidisciplinar e formado por quadros de origens diversas (Brasília, Porto Alegre, consultoria internacional), representou não somente chance de obter alguma experiência técnica e profissional. Possibilitou, como se revelaria valioso para mim no futuro próximo, contato com problemas que me pareciam de fato estimulantes.

Nesse mesmo período, a Prefeitura instalou o Instituto de Planejamento Urbano de Florianópolis (IPUF), instituição em atividade até os dias de hoje e que foi concebida - tendo assim funcionado durante muitos anos - como, por assim dizer, centro de gravidade das atividades de planejamento e promoção do desenvolvimento urbano e regional no seu território de jurisdição. A escala municipal (do município criador) era priorizada nessas atividades, mas, conforme exigido pelas questões ou circunstâncias, operava-se no nível regional, correspondente ao Aglomerado Urbano de Florianópolis (AUF). 
Esse aglomerado abrange, além da capital catarinense, também os municípios de São José, Biguaçu e Palhoça. Suas dimensões, todavia, eram flexíveis. Por exemplo, em estudos e análises sobre turismo, visando os correspondentes planejamento e promoção, o AUF atingia municípios próximos entre cujos atributos figuram águas termais (Santo Amaro da Imperatriz e Águas Mornas).

Daí que, no desenvolvimento do Programa Cidades de Porte Médio, executado entre meados dos anos 1970 e o início dos 1980, com recursos majoritariamente oriundos do Banco Mundial, o leque de planos e projetos não só era bastante diversificado como recobria território que transbordava as dimensões da área em processo de conurbação em torno de Florianópolis. Assinale-se que tal programa representou, talvez, o principal feixe de atividades técnicas, sobretudo em planejamento, nas quais o IPUF se envolveu em toda a sua existência.

Terminado o grosso dos trabalhos da equipe criada para lidar com o transporte urbano, o recém surgido IPUF absorveu o contingente técnico daquele grupo que tinha origem local. Esses profissionais passaram a fazer parte de coletivo razoavelmente numeroso e com formação multidisciplinar, como é de costume nas instituições dedicadas ao planejamento urbano e regional. Com efeito, além de economistas (bastante minoritários nesse caso), havia - pelo que a lembrança permite assinalar - ao menos geógrafos, arquitetos, engenheiros, sociólogos, assistentes sociais, administradores e advogados.

Nesse grupo, predominavam técnicos bastante jovens e com experiência em planejamento urbano e regional claramente heterogênea. Ouso assinalar, olhando retrospectivamente, que essa diferenciação respeitava não só à familiaridade com o planejamento, no que essa atividade tem de conteúdo técnico e político. Relacionava-se também à prática do estudo e da reflexão sobre o que, quase quarenta anos atrás, compunha leque de assuntos centrais da problemática urbana e regional, quer em Santa Catarina, no sul do Brasil ou no país como um todo.

Com referência ao que mais diretamente implicava o recém-formado IPUF, esses assuntos eram variados. Abrangiam problemas como: processos acelerados de verticalização e adensamento na área central de Florianópolis; avanço na urbanização de localidades da Ilha de Santa Catarina externas à área central (em regra, litorâneas); grandes obras de infraestrutura (mediante conquista de terras ao mar, com aterros que sustentariam rodovias e outros equipamentos); rapidez na ocupação do maciço de morros próximos à área central de Florianópolis, multiplicando as comunidades carentes; "descoberta" das praias do norte e do leste da Ilha de Santa Catarina pelo turismo; veloz crescimento populacional em outros 
municípios da área conurbada - em primeiro lugar São José, com inacreditáveis taxas nos anos 1970, e Biguaçu e Palhoça prefigurando o que viria a acontecer posteriormente.

Esse turbilhão, que, com as diferenças próprias às circunstâncias de lugar e tempo e às especificidades locais, foi registrado em outras cidades de porte médio no Brasil, representava não poucos desafios para corpo técnico às voltas com a responsabilidade de "apreender" os problemas e planejar o desenvolvimento. Alguma base para orientar o olhar indagativo e sustentar a reflexão, dando ordenamento mental ao que se observava ou intuía, mostrava-se necessária.

Foi nesse ambiente e em face dessas condições que um integrante da equipe do IPUF, economista que em 1978 defenderia dissertação de mestrado no Programa de Pós-Graduação em Planejamento Urbano e Regional da Universidade Federal do Rio Grande do Sul, recomendou a leitura de Economia Política da Urbanização.(1976) Na esteira da sua experiência como estudante de pós-graduação, em curso voltado, pode-se considerar, a tipos de assuntos que integravam o campo de atuação do IPUF, o colega não deixou de assinalar quando sugeriu o livro (lançado alguns anos antes): "não sei para que recorrer a autores de fora, se temos disponível um livro como esse...”, um comentário que provavelmente refletia opiniões captadas junto a seus professores e resultava da comparação com outras bibliografias então em uso.

Comprei o livro imediatamente. Ato contínuo, cada ensaio (são sete, contando o intitulado "À guisa de introdução: urbanização e classes sociais") foi lido. E relido, meticulosamente, pois a experiência dessa leitura significava a penetração em áreas temáticas que até então me eram pouco familiares, tendo em vista, pelo menos parcialmente, o caráter da formação universitária que havia obtido. Logo percebi que os problemas abordados tinham presença no Brasil, de uma maneira ou de outra, até em literatura não acadêmica. Duas ilustrações bastariam a esse respeito.

Monteiro Lobato escreveu o que segue em conto de 1906 intitulado "Cidades mortas", ambientado no interior do Estado de São Paulo implicado em processos ligados à economia do café.

A quem em nossa terra percorre tais e tais zonas, vivas outrora, hoje mortas, ou em via disso, tolhidas de insanável caquexia, uma verdade, que é um desconsolo, ressurte de tantas ruínas: nosso progresso é nômade e sujeito a paralisias súbitas. [...] Conjugado a um grupo de fatores sempre os mesmos, reflui com eles duma região para outra. Não emite peão. [...]. Emigra, deixando atrás de si um rastilho de taperas. (LOBATO, 1969, p. 3) 
Na literatura regionalista do paraibano José Américo de Almeida, a vida numa fazenda com engenho de açúcar, no final do século XIX, é descrita em romance que apresenta passagens como esta.

Era o êxodo da seca de 1898. Uma ressurreição de cemitérios antigos - esqueletos redivivos, com o aspecto terroso e o fedor das covas podres.

Os fantasmas estropiados como que iam dançando, de tão trôpegos e trêmulos, num passo arrastado de quem leva as pernas, em vez de ser levado por elas.

Andavam devagar, olhando para trás, como quem quer voltar. Não tinham pressa em chegar, porque não sabiam onde iam. (ALMEIDA, 1988, p. 4)

Na minha experiência, a leitura de Economia Política da Urbanização (1976) representou chance de, e estímulo para, dirigir o olhar com lentes acadêmicas em direção a assuntos com os quais o meu contato ocorrera tão somente, em boa medida, ao sabor do usufruto da prosa ficcional. Cidades mortas (LOBATO, 1969) e A bagaceira (ALMEIDA, 1988), para ficar no par de ilustrações apresentadas, vieram à mente quando da leitura de "Migrações internas: considerações teóricas sobre o seu estudo" (1976), um dos ensaios do referido livro de Paul Singer.

Dialogando com autores estrangeiros, entre eles, com destaque, Gunnar Myrdal (MYRDAL, 1968), Singer expõe importantes considerações sobre os processos que subjazem aos movimentos de pessoas no espaço, particularmente com origem nas áreas rurais. Cabe assinalar o realce atribuído ao fato de processos contrários poderem resultar no mesmo tipo de resultado, qual seja, a migração desde o campo. De fato:

Os fatores de expulsão que levam às migrações são de duas ordens: fatores de mudança, que decorrem da introdução de relações de produção capitalistas nestas áreas, a qual acarreta a expropriação de camponeses, a expulsão de agregados, parceiros e outros agricultores não proprietários, tendo por objetivo o aumento da produtividade do trabalho e a consequente redução do nível de emprego [...]; e fatores de estagnação, que se manifestam sob a forma de uma crescente pressão populacional sobre uma disponibilidade de áreas cultiváveis que pode ser limitada [...]. (SINGER, 1976 , p. 38 - grifo do autor).

Embora com significados econômicos opostos - num caso, expansão econômica, no outro, como o nome informa, estagnação, ou mesmo declínio -, ambas as categorias de fatores produzem migrações.

Os fatores de mudança provocam um fluxo maciço de emigração que tem por consequência reduzir o tamanho absoluto da população rural. Os fatores de estagnação levam à emigração de parte ou da totalidade do acréscimo populacional devido ao crescimento vegetativo da população rural, cujo tamanho absoluto se mantém estagnado ou cresce apenas vagarosamente. (SINGER, 1976, p. 38). 
No Brasil dos anos 1960 em diante, com os desdobramentos da Revolução Verde na agricultura e a crescente presença de relações capitalistas em numerosas áreas rurais, em percurso de várias décadas até os dias atuais - testemunhando-se uma enorme progressão no cultivo de grãos para fins industriais -, essas formulações de Paul Singer têm lugar importante como instrumentos que auxiliam a decifrar situações observadas. Mais de uma vez o autor salientou a necessidade de detectar e distinguir, nas análises, as razões de índole estrutural das migrações. E sublinhou que estas devem ser entendidas como um processo social: "Quando uma classe social se põe em movimento, ela cria um fluxo migratório que pode ser de longa duração e que descreve um trajeto que pode englobar vários pontos de origem e de destino." (SINGER, 1976, p. 52).

A apreensão analítica da geografia das migrações ganha em profundidade quando se detectam os fatores de atração, pois são estes "[...] que determinam a orientação destes fluxos e as áreas às quais se destinam." (SINGER, 1976, p. 40). Tais fatores dizem respeito, em primeiro lugar e de longe, à demanda por trabalho, assimilada à ideia de perspectivas outorgadas pelo crescimento econômico. Os movimentos da economia respondem, portanto, pelo essencial da espacialidade da população. Examinando, em outro estudo, o quadro brasileiro nos anos 1970, Singer (1982, p. 37) declara, com efeito: "Nossa hipótese é que [...] foi o crescimento da indústria que condicionou a distribuição espacial da população neste período."

De todo modo, a cidade, em termos gerais o meio urbano, sobressai inquestionavelmente na espacialidade da dinâmica demográfica, seja no Brasil ou em outros países, do centro do capitalismo ou não. Realmente, mesmo que a atividade industrial seja-lhe rarefeita, um tecido urbano - ainda mais quando correspondente à sede do poder público estadual - acaba sinalizando possibilidades para contingentes às voltas com a retração das possibilidades de reprodução social nas suas áreas de origem, mormente em meio rural. A vida urbana magnetiza, quase invariavelmente, as atenções de quem busca melhores condições de vida.

Tal situação exibe notável ilustração em Santa Catarina, sendo Florianópolis o principal caso em questão. A economia é essencialmente terciária em Florianópolis, em termos históricos. Assim, a cidade que é a capital de Santa Catarina contrasta com áreas urbanas surgidas no território estadual por conta das migrações de origem europeia no século XIX, das quais Joinville e Blumenau atingiram as maiores dimensões e se tornaram verdadeiros bastiões industriais, a primeira na indústria dinâmica (eletrometalmecânica, sobretudo) a segunda na indústria tradicional (têxtil e vestuário, antes de tudo).

Vale notar de passagem que Blumenau foi estudada por Paul Singer em livro intitulado Desenvolvimento econômico e evolução urbana (SINGER, 1977), com primeira edição em 
1969 e correspondente à sua tese de doutorado em Sociologia, elaborada na Universidade de São Paulo sob a orientação do professor Florestan Fernandes. Este, que assina o prefácio do livro, informa que a obra "[...] é a primeira tentativa de investigação sistemática das relações estruturais e dinâmicas do desenvolvimento econômico com a formação e o crescimento das cidades no Brasil.” (FERNANDES, 1977, p. 1). Investigando a trajetória de cinco cidades brasileiras (além de Blumenau, São Paulo, Porto Alegre, Belo Horizonte e Recife), o livro permanece - embora publicado pela primeira vez há quase meio século - uma importante referência sobre as interações entre os movimentos da economia e o espaço, com visão histórica e perspectiva estrutural.

Portanto, destoando dos ambientes industriais que crivam o território catarinense, Florianópolis e sua área de influência mais imediata não deixaram de figurar na geografia dos deslocamentos populacionais com origem no próprio estado e em espaços vizinhos. No interior catarinense, conjugaram-se processos de crescimento no meio rural-como observado, durante certo tempo, a reboque da agroindústria de carnes no grande oeste catarinense, um setor que depois (anos 1990, notadamente) se reestruturou e desvinculou propriedades rurais até então integradas, provocando migrações - e de inapelável estagnação ou declínio, como nos planaltos sul e norte do território estadual. Movimentos no vizinho Paraná, principalmente, reforçaram esses resultados. E contingentes vindos do Rio Grande do Sul também passaram a compor o cenário.

Desse modo, o veloz crescimento populacional em Florianópolis e sua região, um dos mais eloquentes aspectos sobre o quanto era desafiador planejar o desenvolvimento em tal área desde os anos 1970, podia ser colocado em perspectiva. Considerar questões desse tipo significava olhar para além da cidade e sua área de influência imediata, situando os "problemas urbanos" em relação a dinâmicas estruturais mais amplas e complexas.

O salto na reflexão, isto é, na capacidade de entendimento sobre material que interpelava a ação técnica (e política), era, dessa forma, favorecido. Com a leitura de Economia Política da Urbanização (1976), enriquecia-se, por conseguinte, a capacidade analítica do corpo técnico e, como desdobramento, fortalecia-se - ao menos potencialmente - a competência do IPUF para desempenhar o papel esperado dessa instituição.

Esse processo foi nutrido também por outros ensaios da obra em foco. Destacou-se nos parágrafos anteriores o estudo sobre migrações internas, que contribui para colocar o crescimento populacional de um tecido urbano em meio a dinâmicas que transcendem amplamente essa escala. Mas o livro igualmente aborda situações urbanas propriamente ditas. 
Uma ilustração é o ensaio "Economia urbana"; outra, aquele intitulado "Aspectos econômicos do planejamento metropolitano".

O segundo ensaio mostrava-se especialmente estimulante, no âmbito do IPUF, em face dos acenos e movimentos protagonizados no plano estadual com vistas à criação de uma Região Metropolitana (RM) no AUF. De fato, tal RM viu a luz no final dos anos 1990, integrada por nove municípios e criada pela Lei Complementar n 162, de 6 de janeiro de 1998; outras duas RM foram criadas nessa mesma iniciativa. Essa lei foi revogada pela Lei Complementar $n^{\circ} 381$, de 7 de maio de 2007. A Lei Complementar $n^{\circ}$ 495, de 26 de janeiro de 2010, instituiu onze RM em Santa Catarina, entre elas a que exibe Florianópolis como centro de gravidade.

Considerando aspectos de domínio estritamente pessoal - ganhando ainda mais força, agora, o caráter de depoimento incrustado neste escrito, aparecendo imbricados o reconhecimento e a gratulação -, a experiência no IPUF foi decisiva para o delineamento da minha trajetória profissional. $\mathrm{O}$ interesse entusiasmado pelas questões urbanas e regionais, ou pela dimensão espacial do desenvolvimento, levou-me a buscar uma condizente formação em pós-graduação. Esta deu-se em dois momentos próximos e sequenciais: um mestrado numa universidade britânica e um doutorado numa universidade francesa, o conjunto das respectivas atividades desdobrando-se sobre a década de 1980. Desde o retorno ao Brasil, pertenço aos quadros da Universidade Federal de Santa Catarina.

Eu provavelmente não teria trilhado esse caminho, caso o roteiro desse relato tivesse sido outro. Nesse percurso, como cuidei de salientar, o contato com a obra de Paul Singer (na sua parte dedicada às questões aqui ressaltadas) revelou-se uma decisiva motivação para despertar e aprofundar o meu interesse pela dimensão espacial do desenvolvimento.

Se "um país se faz com homens e livros”, como disse certa vez Monteiro Lobato, Paul Singer deu sua parte - uma importante parte - de contribuição à edificação do Brasil, sem sombra de dúvida. Deu como cidadão, engajado que foi em processos de melhoria das condições de vida de contingentes necessitados, e como pensador e autor, ajudando a decifrar e a iluminar movimentos da vida social que interpelam a capacidade analítica e o vislumbre de alternativas.

Que o autor Paul Singer permaneça. Que sua obra siga, mais do que na memória, em situação de base para uma contínua fertilização das reflexões sobre o Brasil e sobre outras latitudes nas quais o exercício da abordagem crítica, mirando a transformação, revela-se uma necessidade cotidiana. 


\section{REFERENCIAS}

ALMEIDA, J. A. de. A bagaceira. 25.ed. Rio de Janeiro: Biblioteca do Exército, 1988. [1928]

FERNANDES, F. Prefácio. In: SINGER, P. Desenvolvimento econômico e evolução urbana. 2.ed. São Paulo: Companhia Editora Nacional, 1977, p. 1-5.

FURTADO, C. Formação econômica do Brasil. 22.ed. São Paulo: Editora Nacional, 1987. [1959]

LOBATO, J. B. M. Cidades mortas. In: Cidades mortas. 13.ed. São Paulo: Brasiliense, 1969, p. 3-6. [1906]

MYRDAL, G. Teoria econômica e regiões subdesenvolvidas. 2.ed. Rio de Janeiro: Saga, 1968.

SINGER, P. Desenvolvimento econômico e evolução urbana. 2.ed. São Paulo: Companhia Editora Nacional, 1977.

SINGER, P. Economia política da urbanização. 3.ed. São Paulo: Brasiliense, 1976.

SINGER, P. Crescimento econômico e distribuição espacial da população. Revista de Economia Política, v. 2/3, p. 31-52, 1982. 